\title{
Comparative Evaluation of Probability Distribution Models of Flood flow in Lower Niger Basin
}

\author{
Itolima Ologhadien
}

\begin{abstract}
The choice of optimum probability distribution model that would accurately simulate flood discharges at a particular location or region has remained a challenging problem to water resources engineers. In practice, several probability distributions are evaluated, and the optimum distribution is then used to establish the quantile - probability relationship for planning, design and management of water resources systems, risk assessment in flood plains and flood insurance. This paper presents the evaluation of five probability distributions models: Gumbel (EV1), 2-parameter lognormal (LN2), log pearson type III (LP3), Pearson type III(PR3), and Generalised Extreme Value (GEV) using the method of moments (MoM) for parameter estimation and annual maximum series of five hydrological stations in the lower Niger River Basin in Nigeria. The choice of optimum probability distribution model was made on five statistical goodness - of - fit measures; modified index of agreement (Dmod), relative root mean square error (RRMSE), Nash Sutcliffe efficiency (NSE), Percent bias (PBIAS), ratio of RMSE and standard deviation of the measurement (RSR), and probability plot correlation coefficient (PPCC). The results show that GEV is the optimum distribution in 3 stations, and LP3 in 2 stations. On the overall GEV is the best - fit distribution, seconded by PR3 and thirdly, LP3. Furthermore, GEV simulated discharges were in closest agreement with the observed flood discharges. It is recommended that GEV, PR3 and LP3 should be considered in the final selection of optimum probability distribution model in Nigeria.
\end{abstract}

Index Terms - probability distribution model, optimum, floods, lower Niger River basin, goodness - of - fits.

\section{INTRODUCTION}

Devastating Floods with aftermath of undesirable economic, environmental, and social consequences have become prevalent across the world. Flood disasters account for about $43 \%$ of all the natural disasters, with 3000 disasters, which resulted in 160,000 deaths globally in the last 3 decades. Also, losses amounting to more than US250 billion have had to be borne by societies all over the world to compensate for the consequences of floods according to UNISDR [1] and Kundzewicz [2]. Furthermore, it is estimated that about 800 million people worldwide (i.e., over $11 \%$ of the global populations are currently living in flood prone areas and about 70 million of those people (i.e $10 \%$ of the global population are on the average, exposed to flood each year UNISDR [1]. Similarly, Panda [3] reported that the proportion of the world's population living in flood - prone river basins has increased by $114 \%$, while those living on cyclone - exposed coastlines have grown by

Submitted on January 23, 2021.

Published on February 19, 2021.

Itolima Ologhadien, Department of Civil Engineering, Rivers State University of Science and Technology, Nigeria.

(e-mail: itolima2000@yahoo.com)
$192 \%$ since the 1980s and flooding is the most frequent and greatest hazard for the 633 largest cities or urban agglomerations. The probability of occurrence that such floods occur is an essential input for planning, design, and operation of hydraulic structures and also for estimating the risks involved for the preservation of human life and property according to Smithers [4]. These probabilities of occurrences are estimated with the aid of flood frequency analysis according to Strupczewski [5] and $\mathrm{He}$ [6].

There are two main data types used for flood frequency analysis: annual maximum series (AMS) and partial duration series, sometimes called the peaks -over threshold (POT) series. In the AMS, the largest flood event of each year is selected. The partial duration series consists of all the independent events above a given base value. The POT is used when more than one damaging flood event per year is possible. In this study, the AMS is adopted because, it is consistent with the occurrence of floods in the lower Niger River Basin, wherein, one damaging flood event occurs every year, EM 1110-2- 1450 [7], pp 2, Khaliq et al. [8] and WMO: No.718 [9]. The Nigerian Inland Waterway Authority (NIWA) had performed in-house preliminary data screening using Spearman test for Independence, ManKendal test for trend, the run-test for general randomness and Mann-Whitney Spilt-test for homogeneity. The result from statistical test conducted at 5\% level of significance reveal that the AMS satisfies these assumptions, therefore considered suitable for flood frequency analysis.

The selection of appropriate distribution and parameter estimation is a critical component of flood frequency analysis because a wrong choice of probability model could lead to significant error and bias in flood quantile estimation, particularly at lower exceedance probabilities, leading to either under or over design, which is detrimental to project economy and engineering practice Rahman et al. [10]. Cunnane [11] reported the state-of-the-art review of current practice with regard to use of distribution types for frequency analyses on extremes of precipitation and floods. The Review reported six most frequently used distribution type for flood frequency analysis in the following order of popularity: EV1, LP3, LN2, P3, GEV and Gamma. Furthermore, Cunnane [11] revealed that EV1, LN2, PR3, and LP3 are most globally used distributions while one country used the GEV distribution in spite of its recent popularity. The search for optimum probability distribution among the numerous candidate distributions has generated growing research interest in engineering hydrology. Consequently, each country or agency need to establish the best-fit distribution(s) particular to its geographic setting and the prevalent stochastic processes. [10] studied the selection of probability distribution for at-site flood frequency analysis in Australia and identified LP3, GEV and generalized pareto-distribution (GPO) as the top three 
best-fit distributions. Onoz and Bayazit [12] evaluated various statistical distributions for determination of best-fit probability distribution from 19 stations all over the world and found GEV distribution superior to other six distributions examined. Vogel and Wilson [13] studied the probability distribution of annual maximum, mean, and minimum stream flows in the United States. They found GEV, three parameters lognormal (LN3) and LP3 distributions good approximations to the distribution of annual maximum series. FLOODFREQ cost Action [14] undertook a pan-European comparison and evaluation of methods of flood frequency estimation and found no standardized European flood frequency estimation approach. The study further observed that in a number of countries (i.e., Australia, Germany, Italy and Spain), GEV distribution is among the recommended choices, and a variety of 2- or 3- parameter distributions. Abida and Ellouze [15] studied regional flood frequency distributions for different zones in Tunisia and found the GEV and GLO superior to the other candidate distributions.

Similarly, some of the Flood Frequency studies in Nigeria includes are Ehiorobo and Akpejiori [16], Izinyon and Ajumuka [17], Ibrahim et al. [18] and Mamman et al. [19]. They found LN2, LP3 and EV1 the best-fit distributions. To the best of author's knowledge, no systematic study has been conducted on probabilistic modelling of flood flow for River Niger at Baro, Idah, Lokoja, Onitsha and Asamabiri hydrological stations.

Some of the well - known parameter estimation methods in civil engineering practice for probability distribution functions are (i) Methods of Moments (MoM), (ii) The Maximum Likelihood Method (MLM) and (iii) Probability Weighted Moments Method (PWM) see, Rao and Hamed, [20] and VAN GELDER [21]. In this study, MoM is used because of the simplicity and being relatively easy to apply by equating the sample moments with the moments of the population distribution functions. For example, the LP3 distribution has three parameters: location parameter, shape parameter and a scale parameter. These three parameters are estimated with three indices computed with the sample moments; the sample mean, standard deviation and skew coefficient. In this way the behaviour of the LP3 population parameters may be inferred from the sample data.

The selection of candidate distribution is most commonly based on assessment goodness - of- fit measures using graphical assessments, statistical goodness -of - fit tests, hypothesis-based goodness -of - fit tests and information based criteria. The commonly used statistical indices are (i) Relative Root Mean Square error (RRMSE) (ii) Nash Sutcliffe efficiency (NSE) (iii) Percent bias (PBIAS) (vi) ratio of the root mean square error to the standard deviation of measured data, see Son et al. [22], Moriasi et al. [23] and AMEC Environmental and Infrastructure, [24]. In the hypothesis family are: i) Kolmogorov-Smirnov (KS) tests, ii) Anderson- Darling (AD) test, iii) Probability Plot Correlation and Coefficient (PPCC) tests, iv) Chi-squared test, and v) log-likelihood ratio (t-test and f-test). Information-based criteria including the Akaike Information criterion, Akaike Information Criterion-second order variant (AICc) and Bayesian Information Criterion (BIC). Each method has its strengths and weaknesses when applied to model selection. Karim and Chowdhury [25] compared four probability distributions used in four frequency analysis in Bangladesh using PPCC test, and selected GEV as the best distribution for Bangladesh. [12] applied Chi-squared, Kolmogrov - Smirnov (KS) test, probability plot correlation coefficient (PPCC) test, Anderson - Darling (AD) test and L-Moment diagram to select GEV as best - fit distribution.

Amirataee and Montaseri, [26] evaluated the best regional distribution of monthly rainfall for Northwest Iran using L-Moment and PPCC method. The two methods selected PR3 as the best regional distribution of rainfall data and described PPCC method as powerful single-site test among many goodness-of-fit-test. Amirataee et al. [27] adopted PPCC and L-moment diagram for assessment of goodness of fit methods for determination of best regional probability distribution of rainfall data in Northwest Iran. Onoz and Byazit, [12] applied PPCC for selection of suitable distribution function of low flows in Turkey. Ahn et al. [28] compared PPCC test considering skewness of sample for the GEV Distribution and found PPCC goodness-of-fit better. Chen et al. [29] applied KS, AD, AIC, BIC and AICc goodness - of -fit tests in a comparative study on the selection criteria for fitting flood frequency distribution models with emphasis on upper - tail behavior. There is no established probability distribution model for accurate prediction of flood quantiles in Nigeria, while the country continues to suffer from devastating floods. For example, the 2012 "killer flood" caused 363 fatalities, displaced 7.7 million people, and approximately 600,000 houses were damaged. The "killer flood "amongst other consequences, worsened the existing housing deficit, thus placing huge pressure on all levels of governments to address the sharp increase in infrastructural demand, according to Bilau et al. [30]. The objective of this paper is to evaluate the performances of five commonly used probability distribution models to find the best - fit distribution(s) that would be adopted in practice to represents the statistical characteristics or model the observed flood data in the Lower Niger River Basin. The results of this study may be used in water resources management and design of infrastructure to control the devastating impacts of floods.

\section{Methodology}

\section{A. Probability Distribution Functions}

A total of five probability distributions are considered for the comparative evaluation study. Two of these are two parameter distributions: EVI and LN2 and three-parameter distributions: LP3, PR3 and GEV. These distributions are the most frequently used or recommended frequency distribution types for extremes of both precipitation and floods, see Cunnane, [11] and Onoz and Bayazit, [12]. Table 1 shows the probability distribution models, sample parameters and quantile estimators of the selected distributions.

\section{B. Selection of Parameter Estimation Method}

The study is conducted using a combination of twoparameter distributions (LN2 and EV1) and three parameter distributions (PR3, LP3 and GEV). The PR3, 
LP3 and GEV distribution have three parameters: location parameter $(\beta)$, shape parameter $(\mathrm{k})$ and Scale parameter $(\alpha)$. The distribution parameters, $\beta, \mathrm{k}$ and $\alpha$ are computed from the sample moments: mean, standard deviation and skew coefficient, similarly with the two-parameter distribution. In this study the method of moments (MoM) is adopted. According to the MoM approach, the parameters of the population probability model are estimated by the MoM by equating the sample moments with the moments of population probability model. The $r^{\text {th }}$ moment of a probability distribution model $\mathrm{f}(\mathrm{Q})$, about the origin is given by Rao and Hamed [20] and Naghettini, [31]):

$\mu_{r}^{1}=\int_{-\infty}^{\infty} Q^{1} f(Q) d Q$

where $\mu_{r}^{1}=\mu=$ mean.

The central moments $\mu_{r}$ are computed by:

$\mu_{r}=\int_{-\infty}^{\infty}\left(Q-\mu_{r}^{1}\right)^{r} f(Q) d Q, \mu_{1}=0$

The sample moments $m_{r}^{1}$ and $m_{r}$ are calculated as:

$m_{r}^{1}=\frac{1}{n} \sum_{i=1}^{n} Q_{i}^{r} ; m_{r}^{1}=\bar{Q}$

$m_{r}=\frac{1}{n} \sum_{i=1}^{n}\left(Q_{i}^{r}-\bar{Q}\right)^{r} \quad m_{1}=0$

For correction of sample moments for bias, its conventional moment ratios are defined by Cunnane [11] and Rao and Hamed [20] as:

i) Coefficient of Variation

$\mathrm{C}_{\mathrm{V}}=\mu_{2}^{1 / 2} / \mu_{1}^{1}$

ii) Coefficient of Skewness

$\mathrm{C}_{\mathrm{C}}=\mu_{3} / \mu_{2}^{3 / 2}$

iii) Coefficient of Kurtosis

$$
\mathrm{C}_{\mathrm{K}}=\mu_{4} / \mu_{2}^{2}
$$

\section{Goodness-of-fit-tests}

The goodness - of -fit measures are selected to give sound comparative evaluation study with quantities deemed relevant to objective estimates of the "closeness" of the simulated discharges to observed flood flow. A description of the selected Gof tests can be found in VAN GELDER [21], Son et al. [22], Moriasi et al. [23], Ahn et al. [28], Naghettini [31], Krause et al. [32], Willmot et al. [33], Tao et al. [34], Gupta et al. [35], IN-NA et al. [36], WMO168,[37], and Stedinger et al [38].

1. Nash-Sutcliffe efficiency (NSE)
$\mathrm{NSE}=1-\left[\frac{\sum_{i=1}^{n}\left(Q_{i, o b s}-Q_{i, s i m}\right)^{2}}{\sum_{i=1}^{n}\left(Q_{i, o b s}-Q_{\text {obs }}\right)^{2}}\right] . .-0 \leq \mathrm{NSE} \leq 1.0 \ldots$ (8)

2. RMSE - Observation Standard Deviation Ratio (RSR)

RSR varies from optimal value of 0 , to a large positive value. RSR is calculated as shown in (9):

$R S R=\frac{R M S E}{S T D E V_{o b s}}=\frac{\left[\sqrt{\sum_{i=1}^{n}\left(Q_{i . o b s}-Q_{i, s i m}\right)^{2}}\right]}{\sqrt{\sum_{i=1}^{n}\left(Q_{i . o b s}-\bar{Q}_{s i m}\right)^{2}}}$

\section{Modified Index of Agreement (Dmod)}

The modified Index of Agreement (Dmod) is:

$D \bmod =1-\frac{\sum_{i=1}^{n}\left\|\left(Q_{s i m, i}-Q_{o b s, i}\right)\right\|}{\sum_{i=1}^{n}\left(\left\|Q_{s i m, i}-\bar{Q}_{o b s,}\right\|+\left\|Q_{o b s, i}-\bar{Q}_{o b s,}\right\|\right)}$

$0 \leq \mathrm{Dmod} \leq 1.0$

where $\mathrm{Q}_{\text {sim }}$, is simulated discharges, $\mathrm{Q}_{\mathrm{obs}}$, is observed discharge, and $\bar{Q}_{o b s, i}$ is mean value of observed discharges.

4. Relative-Root-Mean-Square Error (RRMSE)

The RRMS is calculated using (11):

$R R M S=\left[\frac{1}{n-m} \sum_{i=1}^{n}\left(\frac{Q_{o b s, i}-Q_{s i m, i}}{Q_{o b s, i}}\right)^{2}\right]^{\frac{1}{2}}$

\section{Percent Bias (PBIAS)}

The optimal value of PBIAS is 0.0 , with low-magnitude values indicating accurate model simulation.

PBIAS $=\left[\frac{\sum_{i=1}^{n}\left(Q_{i . o b s}-Q_{i, s i m}\right)^{2} * 100}{\sqrt{\sum_{i=1}^{n}\left(Q_{i . o b s}\right)}}\right]$

6. Probability Plot Correlation Coefficient (PPCC) Test The PPCC statistic is calculated as:

$$
r=\frac{\sum_{m=1}^{N}\left(\text { Qobs } . i-\bar{Q}_{o b s}\right)\left(q_{m}-\bar{q}\right)}{\sum_{m=1}^{N}\left(\text { Qobs } . i-\bar{Q}_{o b s}\right)^{2} \sum_{i=1}^{N}\left(q_{m}-\bar{q}\right)^{2}}
$$

where as $\bar{Q}_{o b s}=\frac{1}{N} \sum_{i=1}^{N} Q_{o b s, i}$ and $\bar{q}=\frac{1}{N} \sum_{i=1}^{N} q_{i}$.

The linear coefficient $r$, between the data ranked in ascending order and the theoretical quantiles, where $q_{m}=F_{Q}^{-1}\left(1-P_{i}\right)$, where $\mathrm{P}$ is empirical probability calculated using an appropriate unbiased plotting position formula. 
TABLE 1: Probability Models, SAMPle PARAMETERS AND MOMENTS

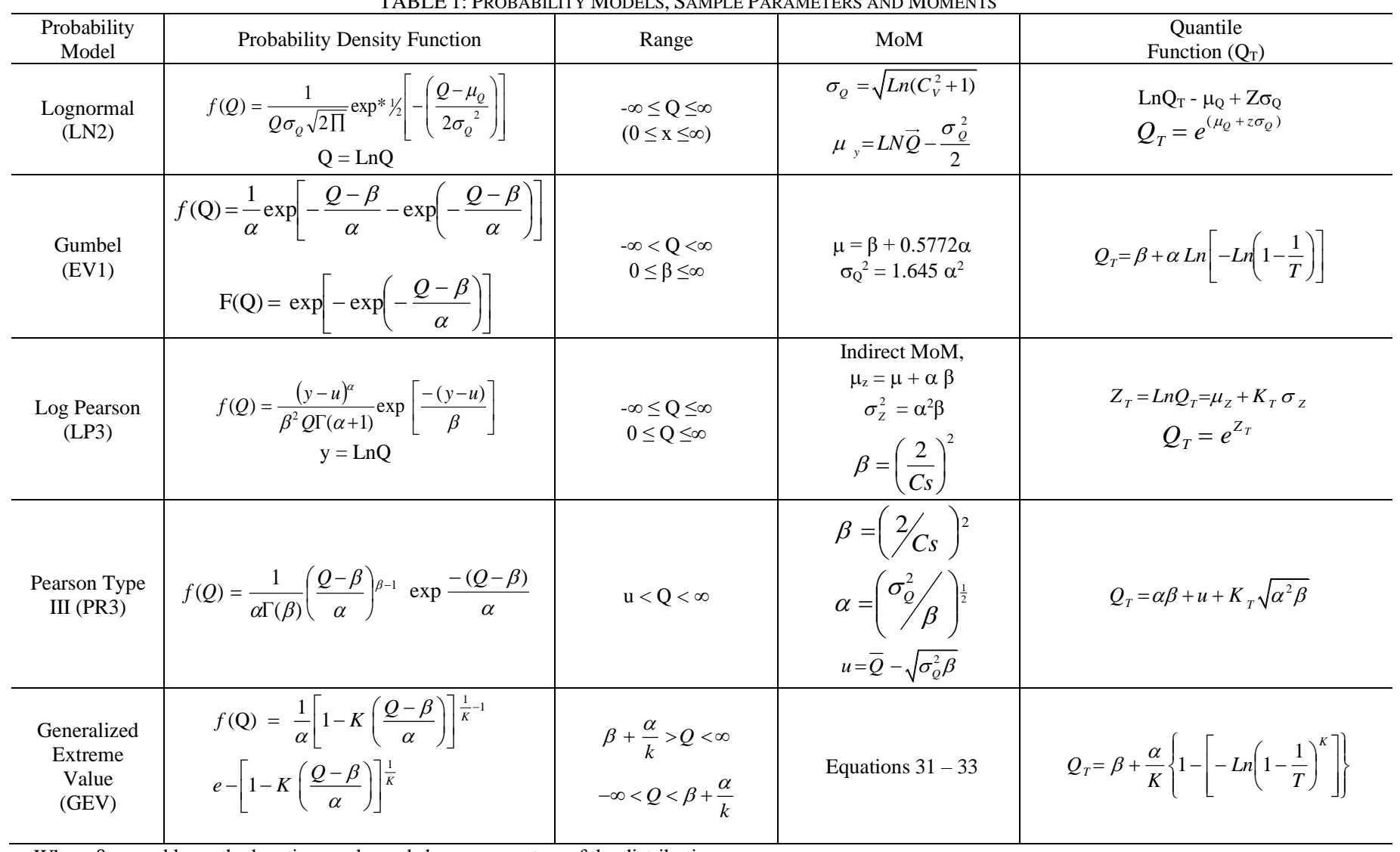

Where $\beta, \alpha$, and $\mathrm{k}$ are the location, scale, and shape parameters of the distributions.

The critical region for the null hypothesis Ho, at significance level $\alpha$, begins at $r_{\text {crit }, \alpha}$ below which, if $r<r_{\text {crit, } \alpha}$ Ho must be rejected in favour of $\mathrm{H}_{1}$. The unbiased plotting position formulas needed for computing the values of $\mathrm{q}_{\mathrm{m}}$ have the general formula, IN-NA [36].

$\mathrm{Pi}=\frac{i-a}{n+1-2 a}$

where "a" varies from 0 to 0.5 ; $\mathrm{Pi}$ is the plotting probability and $i$ is the rank in ordered observation with $i=1$ for the smallest observation in data sample. In Equation 14; when a $=0.375$; Blom formula was used for LN2 distribution, when $\mathrm{a}=0.44$, Gringorten formula was used for Gumbel (EVI) distribution; for $\mathrm{a}=0.4$, Cunnane formula, was used for LP3 and GEV distributions. The unbiased plotting formula for PR3 from WMO168,[37] and Stedinger, [38] was used. $\mathrm{P}=(\mathrm{i}-0.53+0.3 \mathrm{Cs}) /(\mathrm{N}+0.05+0.3 \mathrm{Cs})$, where $\mathrm{Cs}$ is coefficient of skewness, $\mathrm{N}$ is sample size and $\mathrm{i}$ is rank with $\mathrm{i}$ $=1$ indicating the smallest sample number.

\section{Estimation of Flood Quantiles}

The estimation of flood quantiles and related equations for various life expectancies of civil engineering systems can be found in the following texts, Rao and Hamed [20], Naghettini [31], Naghavi [39], Kite [40], Wilson and Hilferty [41], Abramowitz and Stegun, [42]. The exceedance probability is $P\left(Q_{T}>Q\right)=1 / T$. The cumulative probability of non - exceedance is $\mathrm{F}\left(\mathrm{Q}_{\mathrm{T}}\right)$ is given by:

$\mathrm{F}\left(\mathrm{Q}_{\mathrm{T}}\right)=\mathrm{P}\left(\mathrm{Q}_{\mathrm{T}}\langle\mathrm{Q})=1-\mathrm{P}\left(\mathrm{Q}_{\mathrm{T}}>\mathrm{Q}\right)=(1-1 / \mathrm{T})\right.$
Equation 15 is the basis for estimating the magnitude of a flood, $\mathrm{Q}_{\mathrm{T}}$ given its exceedance or non - exceedance probabilities.

The quantile estimate for $\mathrm{T}$ years is calculated by substituting the value of $F=(1-1 / T)$ into the quantile functions in Table 1.

\section{E. Uncertainty Assessment.}

Uncertainty is approximated by the confidence interval of the estimated quantiles of the selected probability distributions at specified return periods. The confidence interval specify the probability that the quantiles estimates lie within the upper and lower confidence interval coefficients; $\mathrm{K}_{\mathrm{Tr}, \beta}$ and $\mathrm{K}_{\mathrm{Tr}, \beta}^{\mathrm{L}}$ using the non - central $\mathrm{t}$ distribution. Confidence limits are computed as follows:

$\mathrm{U}_{\mathrm{Tr}, \beta}(\mathrm{Q})=\bar{Q}+\mathrm{K}_{\mathrm{Tr}, \beta} * \sigma$

$\mathrm{L}_{\mathrm{Tr}, \beta}(\mathrm{Q})=\bar{Q}+\mathrm{K}_{\mathrm{Tr}, \beta} *_{\sigma}$

where $\bar{Q}$, and $\sigma$ are the $\log$ base -10 mean and standard deviation, $\mathrm{U}_{\mathrm{Tr}, \beta}(\mathrm{Q})$ and $\mathrm{L}_{\mathrm{Tr}, \beta}(\mathrm{Q})$ are the upper and lower limits respectively. More details may be found in Rao and hamed [20], p200.

\section{STUdy AREA AND DATA DESCRIPTION}

Annual maximum streamflow data of the five gauging stations were obtain from Nigeria Inland Waterways Authority (NIWA), Lokoja, Nigeria. The gauge stations are 
situated on the River Niger in Nigeria. Table 2 shows the geographical and background information of the five hydrological stations. The AMS of the five hydrological stations have data length of 30 years were used. Table 2, contains the descriptive statistics of the flood data, showing the coefficient of variation (CV) ranging between 0.219 and 0.321 except at Asamabiri with 0.151. Thus year-to-year variation of the AMS is moderately variable. The coefficient of skewness ranges between 0.162 and 0.480 , all positive values, which implies non - normal probability distribution. Furthermore, the fundamental requirement for randomness, independence, homogeneity, and stationarity were tested using the non-parametric tests of turning point, Wald-Wolfswitz, Mann Witney and Spearman Rho, and no empirical evidence was found to rule out the assumptions.

TABLE 2: CHARACTERISTICS OF SELECTED GAUGE STATIONS

\begin{tabular}{|c|c|c|c|c|c|c|c|c|}
\hline$(1)$ & (2) & (3) & (4) & $(5)$ & (6) & (7) & $(8)$ & $(9)$ \\
\hline $\mathrm{S} / \mathrm{N}$ & Stations & Latitude & Longitude & Catchment & \multicolumn{2}{|c|}{ Annual streamflow } & Coeff. of Variation & Skewness \\
\hline & & $(\mathrm{N})$ & (E) & $\mathrm{Km} 2$ & $\mathrm{Max} \mathrm{m}^{3} / \mathrm{s}$ & $\operatorname{Min} \mathrm{m}^{3} / \mathrm{s}$ & $(\mathrm{CV})$ & Cs \\
\hline 1 & Aboh & $05^{\circ} 32^{\prime}$ & $06^{\circ} 31^{\prime}$ & $1,112,830$ & 18671.38 & 850.42 & 0.151 & 0.480 \\
\hline 3 & Idah & $07^{\circ} 06^{\prime}$ & $06^{\circ} 43^{\prime}$ & $1,105,780$ & $26,760.24$ & 826.32 & 0.252 & 0.174 \\
\hline 4 & Lokoja & $07^{\circ} 49^{\prime}$ & $06^{\circ} 44^{\prime}$ & 750,790 & 28,360 & 248.75 & 0.219 & 0.337 \\
\hline 5 & Onitsha & $05^{\circ} 10^{\prime}$ & $06^{\circ} 45^{\prime}$ & $1.135,170$ & $26,607.53$ & 426.84 & 0.237 & 0.164 \\
\hline
\end{tabular}

Extracted from Hydrological Year Book (1914 - 1989): National Inland Waterways Authority, Lokoja, Nigeria.

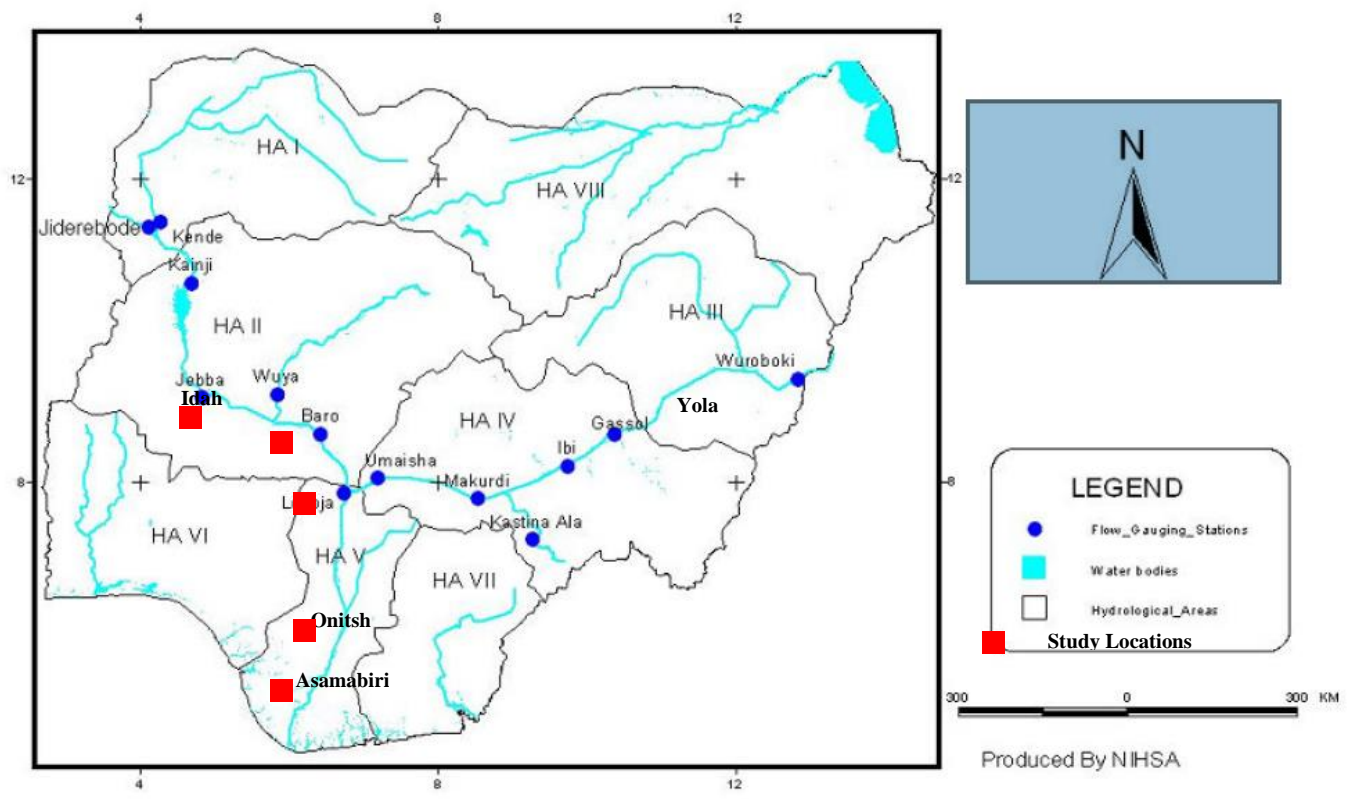

Fig. 1. Hydrological stations (in red squares). (Adapted from Nigerian Hydrological Services Agency (NIHSA), 2014).

\section{RESULTS AND DISCUSSIONS}

\section{A. Quantile Estimates}

The derived quantile relations expressed in the form of $\mathrm{Q}_{\mathrm{T}}-\mathrm{T}$ equation are shown in Table 3. The predictive performances of the probability distribution models were evaluated using the following performance evaluation criteria stated in section $\mathrm{C}$. These indices are recommended standardized guidelines for judging model performance and comparing various models as in ASCE [44] and Moriasi, [23]. Table 4 contains the computed numerical results of the statistical tests. A ranking scheme was devised to rank the distributions according to the optimal value of the statistical index. For example, the distribution with the lowest RRMSE, RSR or PBIAS of zero, Dmod and NSE of one is given a rank of 5 . In case of a tie, equal ranks are given to the competing distributions Accordingly, for each index, the overall ranks associated with each distribution is computed by summing the individual ranks obtained for the hydrological stations.

Columns 8 and 9 of Table 4 present the PPCC calculated test statistics and critical test statistics, at the $5 \%$ significance level across the study stations. The critical test statistics were obtained from various approximating equations, see Naghettini [31], pp. 299-300). Table 4 shows that the 2-parameter distributions; LN2 and EV1 performed better than their 3-parameter counterpart; LP3, PR3, GEV. The decision on the 3-parameter distributions is not compelling, as the PPCC calculated test statistics are very close to their critical values. Fig.2-6 show the graphical plots of observed and simulated discharges of Lokoja station. Figure 6 shows that GEV predictions best simulate the AMS. Similarly, Fig. 7-11 show the Q-Q plots between the AMS, arranged in ascending order and theoretical quantiles calculated using the MS Excel built-in-function: NORM.INV(qm, $\bar{Q}, \sigma)$ where $\mathrm{q}_{\mathrm{m}}$ is probability calculated using the appropriate plotting position formulas, $\bar{Q}$ and $\sigma$, is mean and standard deviation respectively. Due to lack space, the plots for other study stations are not displayed. Table 6 shows the quantile estimates with $95 \%$ confidence interval and computed numerical values. 
TABLE 3: DISTRIBUTION PARAMETER AND QUANTILE RELATIONS

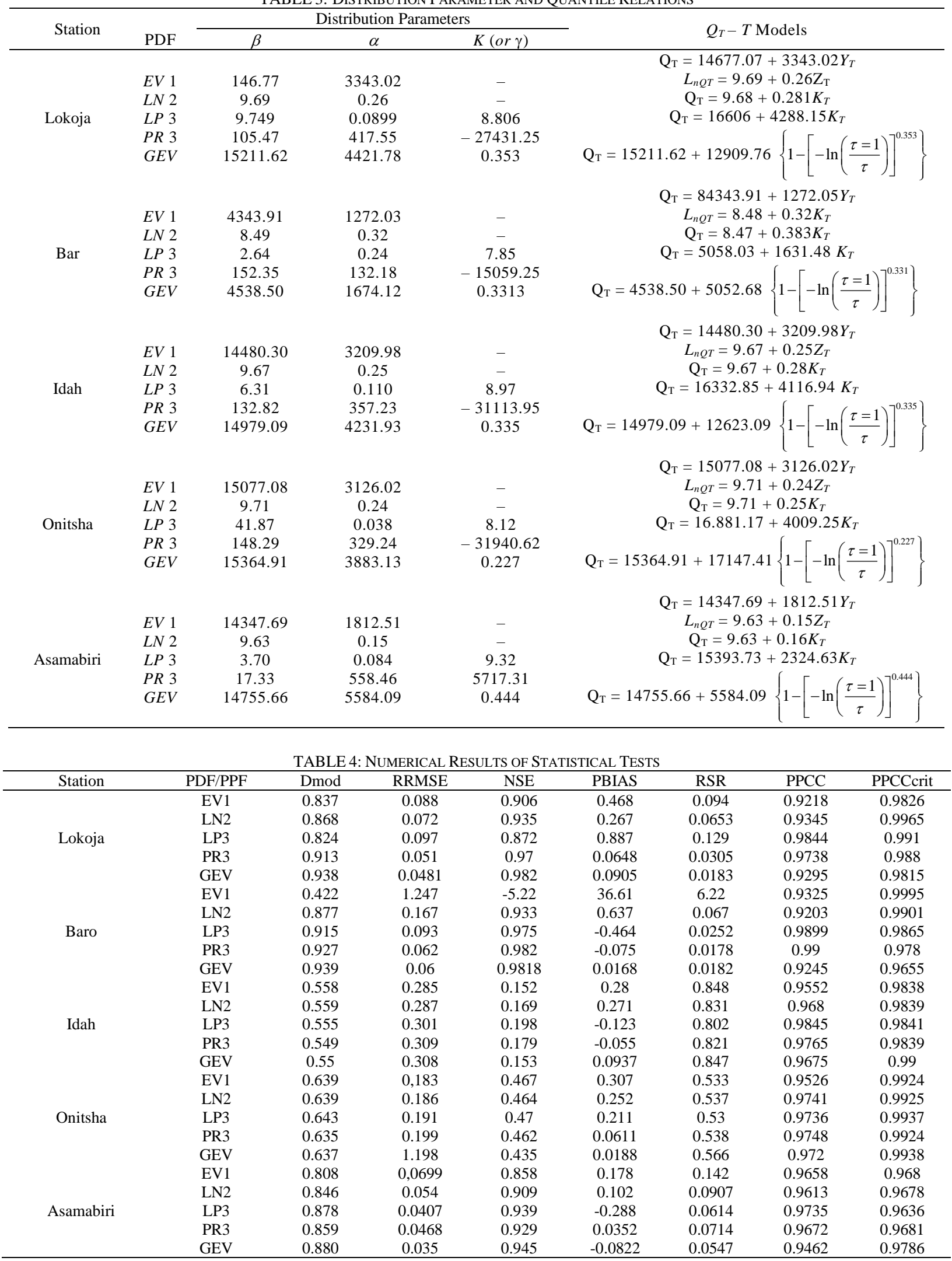


TABLE 5: RANKING SCORES OF PROBABILITY DiSTRIBUTION MODELS AND TOTAL SCORES

\begin{tabular}{|c|c|c|c|c|c|c|c|c|}
\hline Station & PDF & dmod & RRMSE & NSE & PBIAS & RSR & Total Score & PPCC \\
\hline \multirow{5}{*}{ Lokoja } & EV1 & 2 & 2 & 2 & 2 & 2 & 10 & Reject \\
\hline & $\mathrm{LN} 2$ & 3 & 3 & 3 & 3 & 3 & 15 & Reject \\
\hline & LP3 & 1 & 1 & 1 & 1 & 1 & 5 & $\mathrm{Ha}$ \\
\hline & PR3 & 4 & 4 & 4 & 4 & 4 & 20 & $\mathrm{Ha}$ \\
\hline & GEV & 5 & 5 & 5 & 5 & 5 & 25 & Reject \\
\hline \multirow{5}{*}{ Baro } & EV1 & 1 & 1 & 2 & 1 & 1 & 6 & Reject \\
\hline & LN2 & 2 & 2 & 3 & 2 & 2 & 11 & Reject \\
\hline & LP3 & 3 & 3 & 4 & 3 & 3 & 16 & $\mathrm{Ha}$ \\
\hline & PR3 & 4 & 4 & 5 & 4 & 4 & 21 & $\mathrm{Ha}$ \\
\hline & GEV & 5 & 5 & 5 & 5 & 5 & 25 & Reject \\
\hline \multirow{5}{*}{ Idah } & EV1 & 4 & 5 & 1 & 4 & 1 & 15 & Reject \\
\hline & LN2 & 5 & 4 & 3 & 1 & 3 & 16 & Reject \\
\hline & LP3 & 3 & 3 & 5 & 3 & 5 & 19 & $\mathrm{Ha}$ \\
\hline & PR3 & 1 & 1 & 4 & 5 & 4 & 15 & $\mathrm{Ha}$ \\
\hline & GEV & 2 & 2 & 2 & 4 & 2 & 12 & Reject \\
\hline \multirow{5}{*}{ Onitsha } & EV1 & 5 & 5 & 4 & 1 & 4 & 19 & Reject \\
\hline & LN2 & 5 & 4 & 3 & 2 & 3 & 17 & $\mathrm{Ha}$ \\
\hline & LP3 & 4 & 3 & 5 & 3 & 5 & 20 & $\mathrm{Ha}$ \\
\hline & PR3 & 1 & 1 & 2 & 4 & 2 & 10 & $\mathrm{Ha}$ \\
\hline & GEV & 3 & 2 & 1 & 5 & 1 & 12 & Reject \\
\hline \multirow{5}{*}{ Asamabiri } & EV1 & 1 & 1 & 1 & 2 & 1 & 6 & $\mathrm{Ha}$ \\
\hline & LN2 & 2 & 2 & 2 & 3 & 2 & 11 & $\mathrm{Ha}$ \\
\hline & LP3 & 2 & 2 & 4 & 1 & 4 & 17 & $\mathrm{Ha}$ \\
\hline & PR3 & 3 & 3 & 3 & 4 & 3 & 16 & $\mathrm{Ha}$ \\
\hline & GEV & 5 & 5 & 5 & 5 & 5 & 25 & Reject \\
\hline
\end{tabular}

TABLE 6: QUANTILE ESTIMATES WITH 95\% CONFIDENCE INTERVAL FOR NIGER RIVER BASIN

\begin{tabular}{|c|c|c|c|c|c|c|c|}
\hline \multirow{3}{*}{ Station } & \multirow{3}{*}{ Distribution } & \multirow{3}{*}{ Statistics } & \multicolumn{5}{|c|}{ Non Exceedance Probability (F) and Return Period (T) } \\
\hline & & & 0.90 & 0.95 & 0.95 & 0.98 & 0.99 \\
\hline & & & 10.00 & 20.00 & 25.00 & 50.00 & 100.00 \\
\hline \multirow[t]{9}{*}{ Lokoja } & GEV & Lower Limit & 20470.47 & 21719.57 & 22073.27 & 23063.78 & 23928.89 \\
\hline & & Q. estimates & 22155.20 & 23460.49 & 23811.60 & 24735.48 & 25456.57 \\
\hline & & Upper Limit & 24068.15 & 25779.16 & 26273.84 & 27678.38 & 28924.45 \\
\hline & PR3 & Lower Limit & 20736.90 & 22531.13 & 23068.81 & 24651.24 & 26133.46 \\
\hline & & Q. estimates & 22183.88 & 23890.72 & 24395.10 & 25857.49 & 27195.93 \\
\hline & & Upper Limit & 24427.88 & 26919.79 & 27685.58 & 29976.02 & 32158.66 \\
\hline & LP3 & Lower Limit & 20994.30 & 23610.19 & 24455.81 & 27124.39 & 29887.53 \\
\hline & & Q. estimates & 23261.70 & 26589.67 & 27693.20 & 31249.66 & 35034.77 \\
\hline & & Upper Limit & 26730.77 & 31465.89 & 33083.12 & 38433.38 & 44334.99 \\
\hline \multirow[t]{9}{*}{ Baro } & GEV & Lower Limit & 6554.03 & 7037.39 & 7174.63 & 7559.89 & 7897.57 \\
\hline & & Q. estimates & 7193.99 & 7702.66 & 7840.27 & 8204.27 & 8490.71 \\
\hline & & Upper Limit & 7924.86 & 8587.44 & 8779.56 & 9326.43 & 9813.35 \\
\hline & PR3 & Lower Limit & 6554.03 & 7037.39 & 7174.63 & 7559.89 & 7897.57 \\
\hline & & Q. estimates & 7118.63 & 7664.87 & 7821.87 & 8266.19 & 8659.26 \\
\hline & & Upper Limit & 7924.86 & 8587.44 & 8779.56 & 9326.43 & 9813.35 \\
\hline & LP3 & Lower Limit & 6905.72 & 8376.74 & 8891.35 & 10644.89 & 12674.51 \\
\hline & & Q. estimates & 7944.11 & 9903.46 & 10613.02 & 13107.37 & 16119.10 \\
\hline & & Upper Limit & 9606.56 & 12576.41 & 13699.68 & 17818.15 & 23094.83 \\
\hline \multirow[t]{9}{*}{ Idah } & GEV & Lower Limit & 20052.22 & 21264.73 & 21608.68 & 22573.40 & 23417.92 \\
\hline & & Q. estimates & 21666.51 & 22939.36 & 23283.03 & 24190.49 & 24902.60 \\
\hline & & Upper Limit & 23509.64 & 25171.33 & 25652.65 & 27021.54 & 28238.85 \\
\hline & PR3 & Lower Limit & 20052.22 & 21264.73 & 21608.68 & 22573.40 & 23417.92 \\
\hline & & Q. estimates & 21526.75 & 22896.80 & 23290.19 & 24402.56 & 25385.37 \\
\hline & & Upper Limit & 23509.64 & 25171.33 & 25652.65 & 27021.54 & 28238.85 \\
\hline & LP3 & Lower Limit & 20761.14 & 23493.70 & 24388.24 & 27245.33 & 30255.63 \\
\hline & & Q. estimates & 23000.69 & 26481.61 & 27651.84 & 31473.27 & 35618.53 \\
\hline & & Upper Limit & 26430.05 & 31390.30 & 33110.35 & 38885.74 & 45394.56 \\
\hline \multirow[t]{9}{*}{ Onitsha } & GEV & Lower Limit & 20633.37 & 22021.14 & 22424.95 & 23583.36 & 24630.55 \\
\hline & & Q. estimates & 23740.21 & 25291.18 & 25732.53 & 26956.84 & 27993.35 \\
\hline & & Upper Limit & 24045.62 & 25960.19 & 26530.11 & 28189.62 & 29714.79 \\
\hline & PR3 & Lower Limit & 20633.37 & 22021.14 & 22424.95 & 23583.36 & 24630.55 \\
\hline & & Q. estimates & 22084.83 & 23658.97 & 24123.12 & 25466.34 & 26692.51 \\
\hline & & Upper Limit & 24045.62 & 25960.19 & 26530.11 & 28189.62 & 29714.79 \\
\hline & LP3 & Lower Limit & 20657.86 & 22236.28 & 22705.60 & 24075.48 & 25342.35 \\
\hline & & Q. estimates & 22492.45 & 24298.68 & 24836.94 & 26406.81 & 27852.95 \\
\hline & & Upper Limit & 25483.90 & 28189.58 & 29025.67 & 31541.56 & 33961.47 \\
\hline \multirow[t]{9}{*}{ Asamabiri } & GEV & Lower Limit & 17404.51 & 17981.45 & 18140.58 & 18575.75 & 18942.81 \\
\hline & & Q. estimates & 18283.76 & 18846.20 & 18990.20 & 19352.21 & 19615.45 \\
\hline & & Upper Limit & 19326.27 & 20110.95 & 20331.55 & 20942.52 & 21465.42 \\
\hline & PR3 & Lower Limit & 17404.51 & 17981.45 & 18140.58 & 18575.75 & 18942.81 \\
\hline & & Q. estimates & 18226.74 & 18875.79 & 19056.80 & 19555.46 & 19979.69 \\
\hline & & Upper Limit & 19326.27 & 20110.95 & 20331.55 & 20942.52 & 21465.42 \\
\hline & LP3 & Lower Limit & 17765.90 & 19174.85 & 19627.84 & 21050.03 & 22511.46 \\
\hline & & Q. estimates & 18837.55 & 20551.38 & 21115.28 & 22917.78 & 24812.34 \\
\hline & & Upper Limit & 20395.86 & 22684.64 & 23455.98 & 25972.09 & 28689.48 \\
\hline
\end{tabular}




\section{B. Summary of Results}

Table 5 shows the performance ranking of the distributions. The best -fit distribution is identified based on the total score obtained using the statistical indices. Column 7 of Table 5 shows the total scores obtained by each distribution across the study stations. In terms of PPCC Gof test, the 2-parameter distributions have larger margins between the calculated test statistics and critical values than the 3-parameter distributions. Consequently, the decision to reject the null hypothesis for EV1 and LN2 is unquestionable but just satisfactory for GEV. The total scores for each distribution across the stations are graphically displayed in Figures 12 to 16. From Table 5, GEV is the best fit model for Lokoja, Baro and Asamabiri hydrological stations. LP3 is the best - fit model for Idah and Onitsha stations. The results shows that no single probability model emerged the best - fit distribution at all the stations. Figure 17 shows the overall performances with GEV distribution being the optimum distribution, seconded by PR3 and thirdly, LP3. Table 7 shows the quantile estimates with $95 \%$ confidence interval for the hydrological stations for Lower Niger basin. It shows the estimated quantiles lying within the computed ranges of upper and lower confidence limits.

\section{DISCUSSION}

In this study, five probability distribution models used worldwide in flood frequency analysis, namely, GEV, PR3, LP3, LN, and EV1 were chosen to model the AMS of the Lower Niger Basin in Nigeria. The selected models have been evaluated the Gof tests given in section 2.3. The discussion is presented in the following order:

Comparison with previous studies in Nigeria: The hydrological stations evaluated have not been systematically studied. However, two previous studies are worthy of mention, namely, Ibeje [45] conducted flood frequency analysis of Niger River at Shintaku and found LP3, the best - fit distribution. Ehiorobo and Akpejiori[16] conducted similar study at Agenebode using LN2, LP3 and EV1 distributions and found LN2, the best - fit distribution. This study aggresses with Ibeje,[45] who found LP3, the best - fit distribution for Shintaku gauging station. The overall assessment of the candidate's distributions also found LP3, the third best model. But the study disagrees with Ehiorobo and Akpejiori, [16] who found LN2, the best - fit model for Agenebode.

Assessment of GOF tests: The GOF tests performed very well at Lokoja stations. At Baro station, NSE and PBIAS indices performed unsatisfactory, while other indices performed very well. At Idah stations, dmod, RRMSE performed moderately well while NSE performed unsatisfactory for other probability distributions. According to PBIAS index, EV1 LN2 and GEV under predicted the flood discharges, while LP3 and PR3 overpredicted the flood discharges. Furthermore, all the Gof tests performed moderately well for all the distributions at Onitsha study station, and very well at Asamabiri study station. In terms of PPCC statistics, the 2-parameter distributions; EV1 and LN2 performed better than the 3-parameter distributions;
LP3, PR3 and GEV, in summary, Table 5 shows that GEV is best-fit distribution for Lokoja, Baro and Asamabiri stations, LP3 is best-fit distribution for Idah and Ontisha study stations. This observation agrees with [13] who reported that PPCC hypothesis tests are best suited for use with two-parameter distributions. Furthermore, this study agrees with Karim and Chowdhury, [25] who applied RMSDs and PPCC Gof tests to select GEV and LP3, as best-fit distributions for Bangladesh.

Suitability of Selected Distributions: The best-fit distributions found in this study are GEV, PR3 and LP3 distributions. The choice of GEV distribution agrees with [44] who reported that GEV has a convincing relevance to the peak of floods, as most other probability distributions are not true depictions of flood peaks from the theoretical cause - effect standpoint. The GEV distribution is used as standard probability distribution model in 1 country. PR3 is a standard probability model in 7 countries while LP3 in 7 countries, according to Cunnane [11]

\section{SUMMARY AND CONCLUSION:}

This paper presents the comparative evaluation of probability distribution models of flood flow in Lower Niger River Basin, using five probability distribution models: EV1, LN2. LP3. PR3 and GEV. A total of six goodness-of-fit tests are adopted: Dmod, RRMSE, NSE, PBIAS, RSR and PPCC to identify the best-fit probability distribution model with MoM for parameter estimation. AMS from five hydrological stations were used for the study with GEV distribution identified as the best-fit distribution for Lokoja, Baro and Asamabiri stations while LP3 for Onitsha and Idah study station. On overall assessment, GEV is the best-fit distribution, seconded by PR3 and thirdly, LP3. The study recommends the development of a regional GEV, PR3 and LP3 distributions using the existing hydrological map of Nigeria which had demarcated the country into eight homogenous hydrological regions. The results of this study would be useful for at site flood frequency analysis on other stations in the lower Niger river basin.

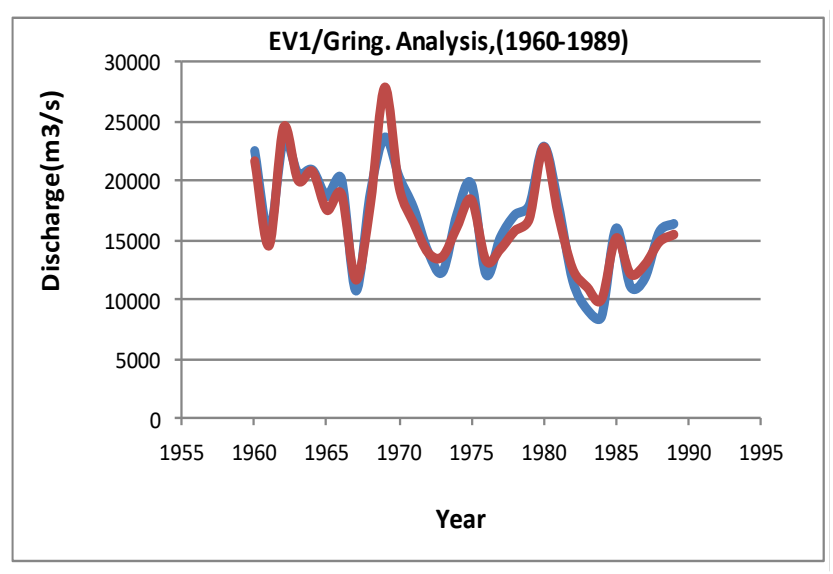

Fig. 2. Observed and Simulated Discharges (Lokoja). 


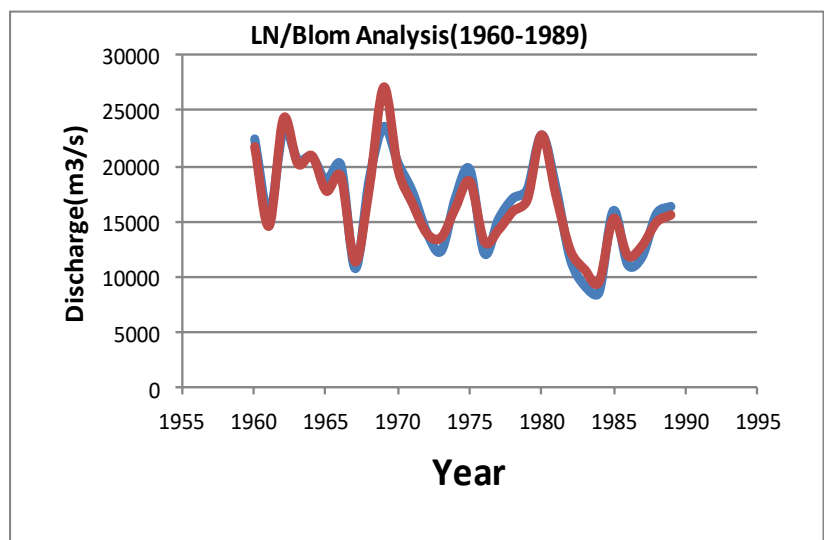

Fig. 3. Observed and Simulated Discharge (Lokoja).

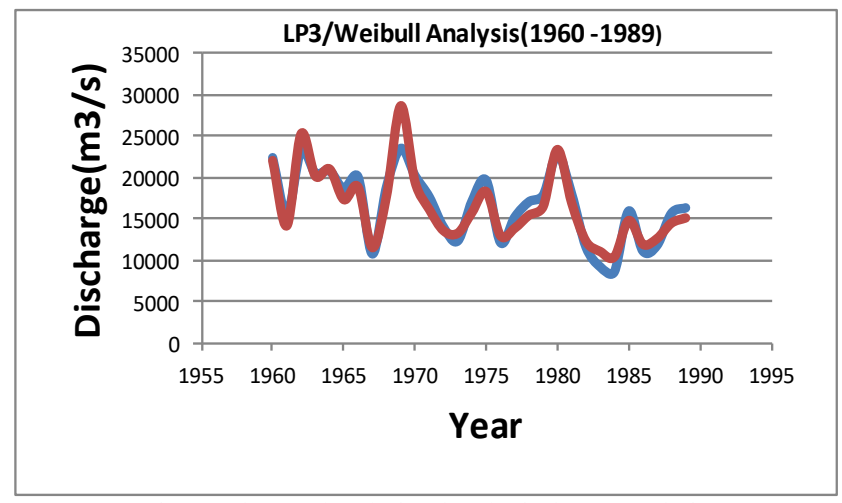

Fig. 4. Observed and Simulated Discharge (Lokoja).

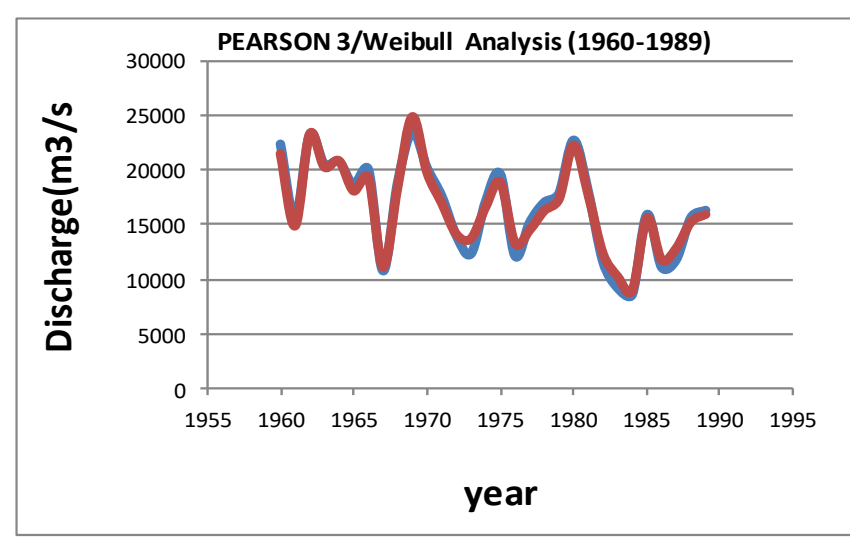

Fig. 5. Observed and Simulated Discharge (Lokoja).

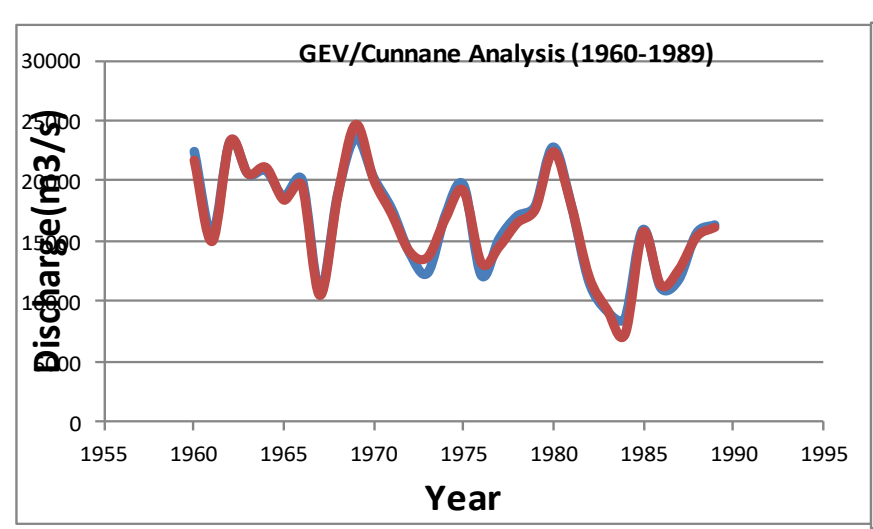

Fig. 6. Observed and Simulated Discharge (Lokoja).

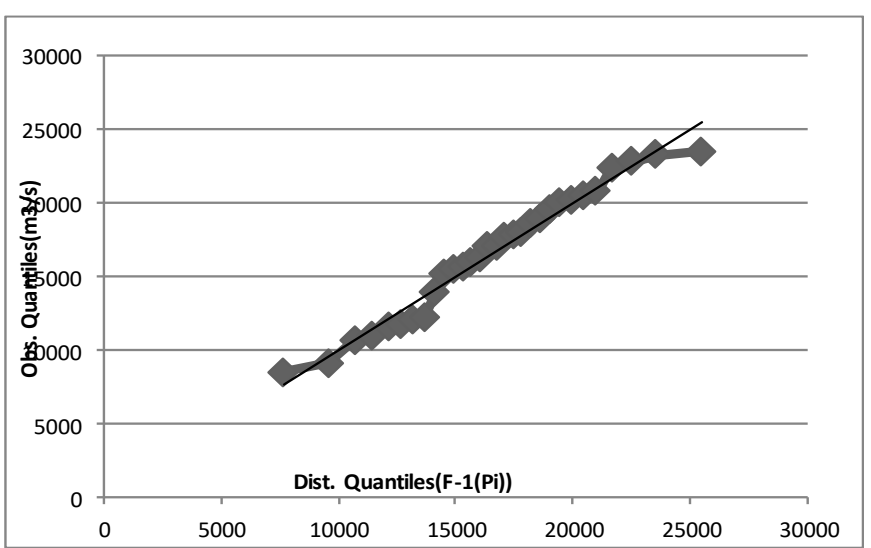

Fig. 7. EVI Q-Q Plot for Flood Flow, Lokoja.

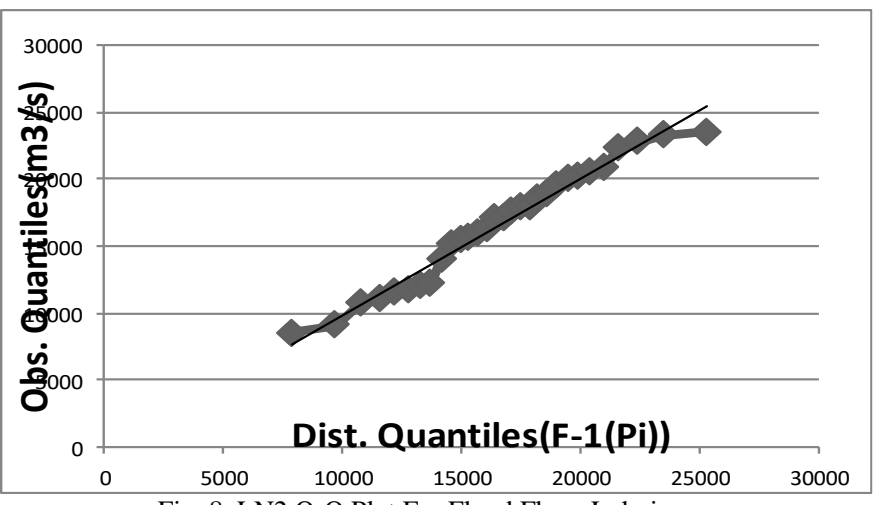

Fig. 8. LN2 Q-Q Plot For Flood Flow, Lokoja.

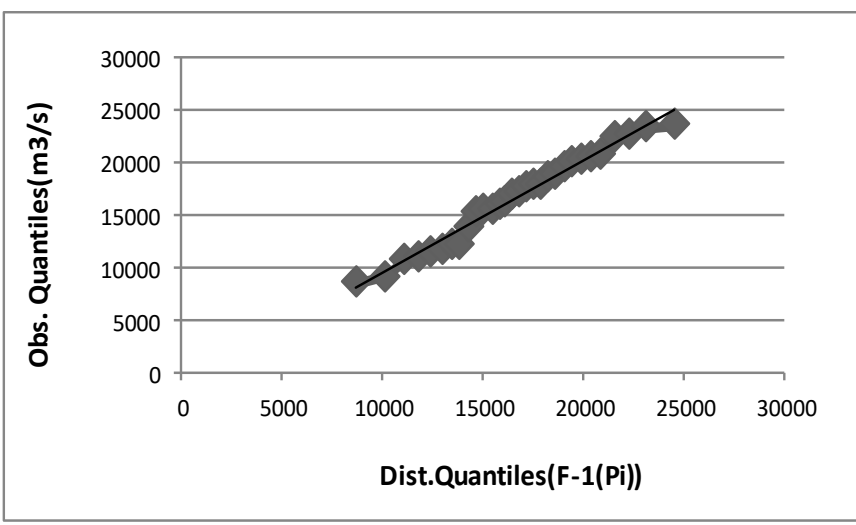

Fig. 9. LP3 Q-Q Plot For Flood Flow, Lokoja.

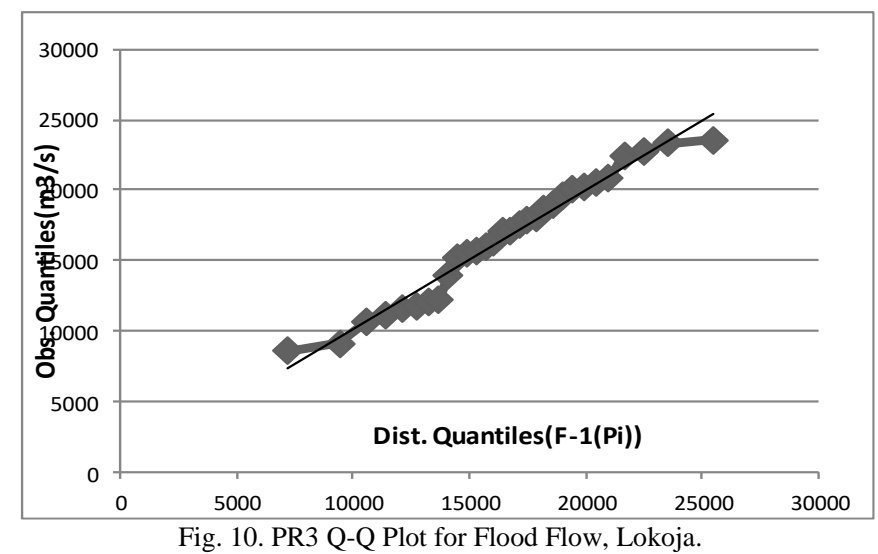

Fig. 10. PR3 Q-Q Plot for Flood Flow, Lokoja. 


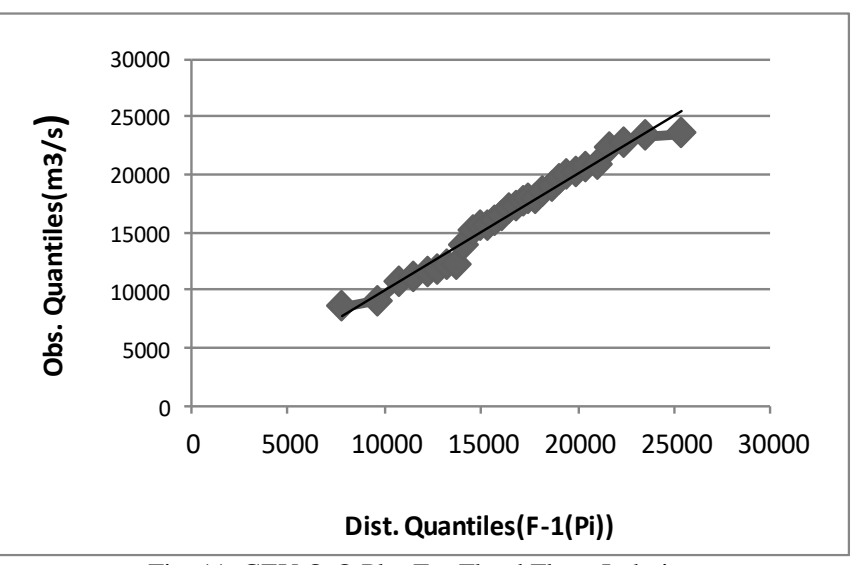

Fig. 11. GEV Q-Q Plot For Flood Flow, Lokoja.

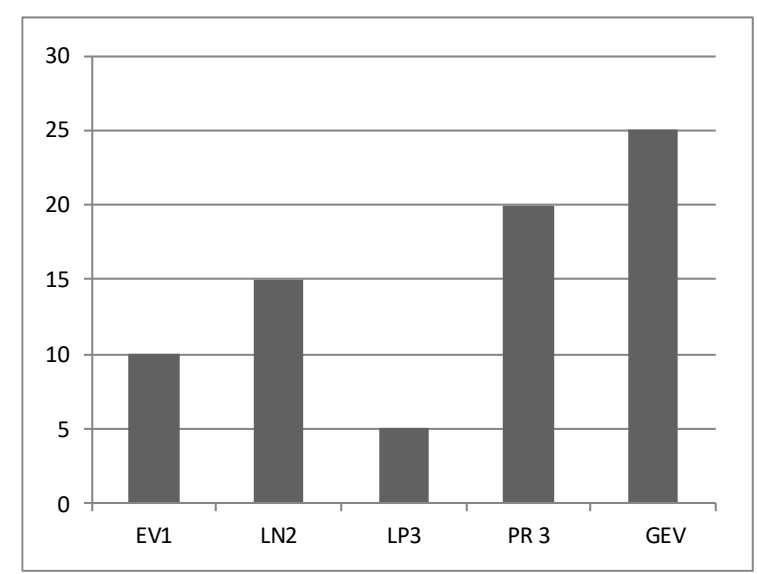

Fig. 12. Goodness -of-Fit Scores for Lokoja.

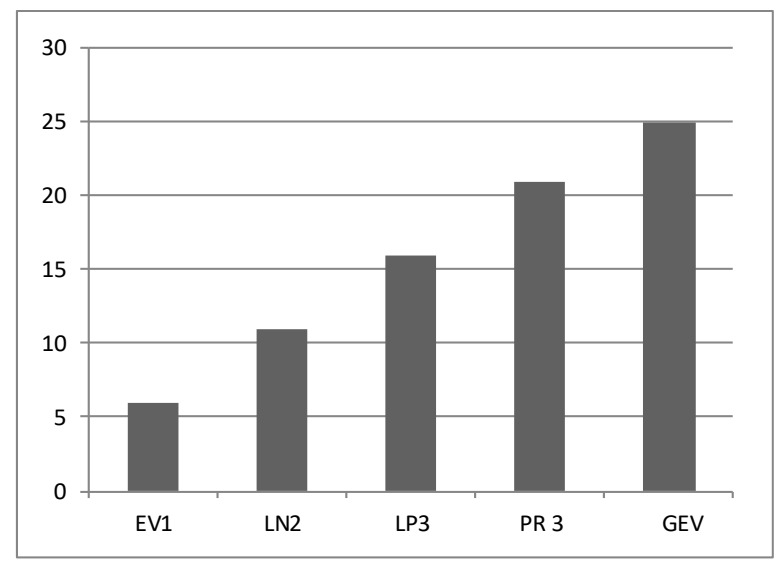

Fig. 13. Goodness -of-Fit Scores for Baro.

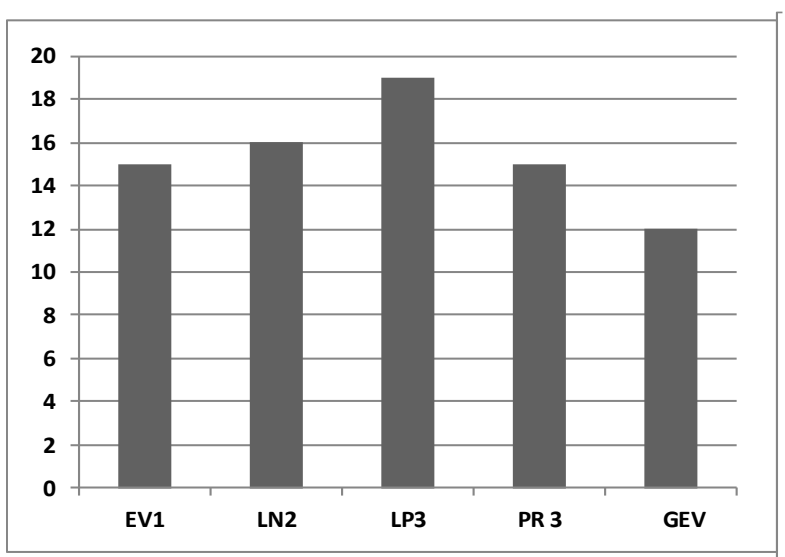

Fig. 14. Goodness -of-Fit Scores for Idah.

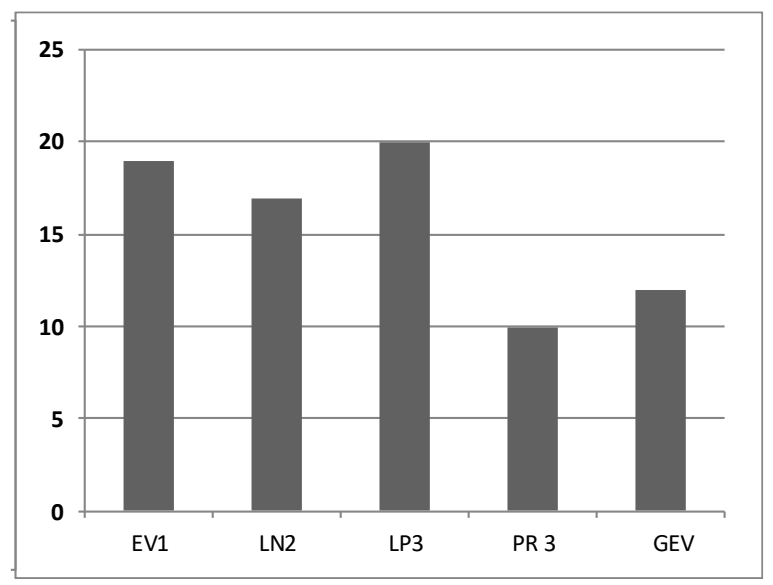

Fig. 15. Goodness -of-Fit Scores for Onitsha.

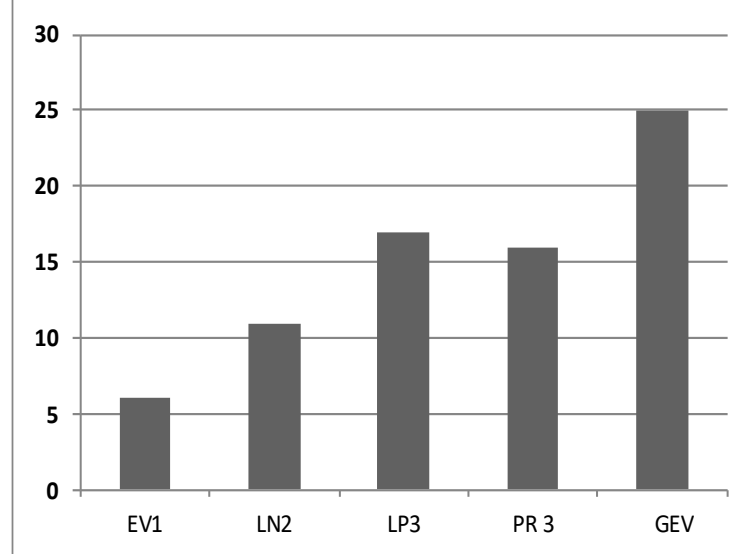

Fig. 16. Goodness -of-Fit Scores for Asamabiri.

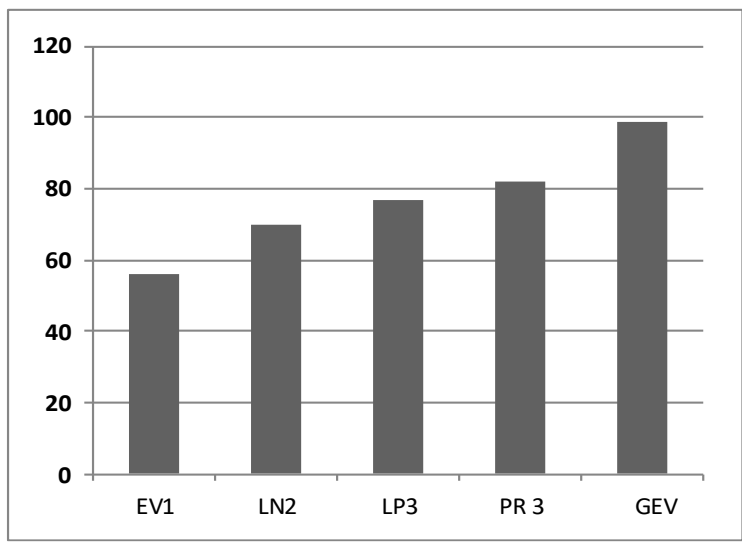

Fig. 17. Goodness -of-Fit Total Scores for all Stations.

\section{REFERENCES}

[1] UNISDR (United Nations International Strategy for Disaster Reduction), 2011. Revealing risk, redefining development. Geneva: UNISDR.

[2] Kundzewicz, Z.W., et al., 2013. Flood risk and climate change: global and regional perspectives. Hydrological Sciences Journal, $59(1), 1-28$.

[3] Panda, A. and Amaratunga, D. (2019) Resilience Cities, Oxford Research Encyclopedia of Hazard Science, DOI:10.1093/acrefore/ 9780199389407.013.321.

[4] Smithers, J.C. (2012). Methods for design flood estimation in South Africa. http.//dx.doi.org/10.4314/wsa.v38i4.19, Water SA Vol.38 No.4, pp.633 - 644 .

[5] Strupczewski, W.G., Singh, V.P., and Weglarczyk, S., 2002.Asymptotic bias of estimation methods caused by the assumption of false probability distribution. Journal of Hydrology, 258 (1-4), 122-148. doi:10.1016/S0022-1694(01)00563-7.

[6] He, J., Anderson, A., and Valeo, C (2015), Bias compensation in flood frequency analysis, Hydrological Sciences Journal, 60(3) 381 397. http://dx.doi.org/10.1080/02626667.2014.885651. 
[7] EM 1110-2-1450(1994). Hydrologic Frequency Estimates, U.S Army Corps of Engineers, Washington, DC 20314-1000.

[8] Khaliq, M.N., Ouarda, T.B.M.J., Ondo, J.-C., Gachon, P., and Bobee, B. (2006). Frequency analysis of a sequence of dependent and/or non-stationary hydro - meteorological observations: A review, Journal of Hydrology, 329, pp.534-552.

[9] WMO: No.718, 1989 (World Meteorological Organization). (1989). Statistical distributions for flood frequency analysis. Geneva: World Meteorological Organization.

[10] Rahman A.S, Rahman, A. Zaman M.A., Haddad K., Ahsan A., Imteaz M. (2013), A study on selection of probability distributions for at - site flood frequency analysis in Australia, Nat Hazards (2013) 69:1803 -1813. DOI 10.1007/s11069-013-0775-y.

[11] Cunnane, C., (1989). Statistical Distribution for Flood Frequency Analysis. Operational Hydrol. Rep. 33, World Meteorological Organisation, Geneva.

[12] Onoz, B. and Bayazit, M. (1995), Best-fit distributions largest available flood samples, Journal of Hydrology, 167 (1995), 195-208.

[13] Vogel, R.M. and Wilson, I. (1996). Probability Distribution of Annual, Maximum, Mean, and Minimum Streamflows in the United States. Journal of Hydrologic Engineering, Vol.1, No. 2, pp. 69-76.

[14] FLOODFREQcost Action ES0901, Review of Applied-Statistical Methods for Flood - Frequency Analysis in Europe (WG2).

[15] Abida H. and Ellouze M (2007), Probability distribution of flood flows in Tunisia, Hydrol. Earth Syst. Sci. Discuss., 4, 957-981.

[16] Ehiorobo J.O. and Akpejiori I.J (2016), Flood Frequency Analysis of River Niger at Agenebode, Edo State, Nigeria, Journal of the Nigerian Association of Mathematical Physics, Volume 38, pp.309318.

[17] Izinyon, O.C., and Ajumuka, H.N., (2013). Probability distribution models for flood prediction in Upper Benue River Basin- Part II Civil and Environmental Research, Vol. 3, No.2, pp.62-74.

[18] Ibrahim U.A, Yadima S.G, Nur Alkali A (2016) Flood Frequency Analysis at Hadejia River in Hadejia-Jama'are River Basin, Nigeria, Civil and Engineering Research, Vol.8. No.9., ISSN 22245790(Paper) ISSN 2225-0514(Online)

[19] Mamman M.J, Otache Y.M, Ibrahim J, Shaba M.I (2017), Evaluation of Best -Fit Probability Distribution Models for the Prediction of Inflows of Kanji Reservoir, Niger State, Nigeria, Air, Soil and Water Research, Volume 10: 1-7, DOI:10.1177/117862211768 1034.

[20] Rao A.A and Hamed K.H (2000), FLOOD FREQUENCY ANALYSIS, CRC Press, ISBN 0-412-55280-9.

[21] VAN GELDER, P.H.A.J.M. WANG, W., and VRIJLING, J.K (2007). Statistical Estimation Methods for Extreme Hydrological Events in Vasiliev, O.F et al. (eds.) Extreme Hydrological Events: New Concepts for Security, 199-252. 2007 Springer.

[22] Son, K., Lin, L., Band, L., and Owens, E.M. (2019). Modelling the interaction of climate, forest ecosystem, and hydrology to estimate catchment dissolved organic carbon export. Hydrological processes. 2019; 33:1448-1464.https://doi.org/10.1002/hyp.13412

[23] Moriasi, D.N., Gitau, M.W., Pai, N., and Daggupati. P. (2015) Hydrologic and Water Quality Models:Performance Measures and Evaluation Criteria. Transactions of the American Society of Agricultural and Biological Engineers, Vol. 58(6): 1763-1785.

[24] AMEC Environmental \& Infrastructure (2014). Frequency Analysis Procedures for Stormwater Design Manual, CW2138.

[25] Karim, M.D.and Chowdhury (1995). A comparison of four distributions used in flood frequency analysis in Bangladesh. Hydrological Sciences Journal, 40(1), pp.55-66.

[26] Amirataee, B. and Montaseri, M. (2013). Evaluation of L-Moment and PPCC Method to Determine the Best Regional Distribution of Monthly Rainfall Data: Case Study Northwest of Iran. Journal of Urban and Environmental Engineering, v.7, n.2. pp. 247-252.

[27] Amirataee, B., Montaseri, M. and Rezael, H. (2014). Assessment of Goodness of Fit Methods in Determining the Best Regional Probability Distribution of Rainfall Data. International Journal of Engineering, IJE Transactions A: Basics Vol. 27, No. 10, pp. $1537-$ 1546 .

[28] Ahn, H., Kim, S., Lee, J., and Heo, J.-H. (2020). Regression equations of probability plot coefficient test statistics using machine learing, EGU General Assembly 2020 https://doi.org/10.5194/egusphere-egu2020-12315.

[29] Chen, X., Shao, Q., Xu, C-Yu., Zhang, J., Zhang, L., and Ye, C. (2017). Comparative Study on the Selection Criteria for Fitting Flood Frequency Distribution Models with Emphasis on Upper - Tail Behavoiur, water 2017, 9, 320; doi:10.3390/w9050320.

[30] Bilau A. A, Witt E, Lill I, Bustani S. A. (2012), Housing Reconstruction Following the 2012 Nigerian Floods: Was it Built Back Better? in Prins, M., Wamelink, H., Giddings, B., Ku,K., and Feenstra, M.(Eds.)(2016).Proceeding of the CIB World Building
Congress 2016: Volume II-Environmental opportunities; Constructing Commitment and Acknowledging Human Experiences .(Tampere University of Technology. Department of Civil Engineering. Construction Management and economics. Report; Vol. 18). Tampere University of Technology.

[31] Naghettini, M (ed). Fundamentals of Statistical Hydrology, ISBN 978 $-3-319-43561-9$, Springer.

[32] Krause, P., Boyle, D.P., and Base, F. (2005). Comparison of different efficiency criteria for hydrological model assessment, advances in Geosciences, 5, pp.89-97.

[33] Willmott, C.J., Robeson, S.M. and Matsuura, K. (2012). Short Communication: A refined index of model -performance. Int. J. Climatol. 32: 2088-2094(2012).

[34] Tao, D.Q., Nguyen, V-T-V and Bourque, A. (2002). On selection of probability distributions for representing extreme precipitation in southern Quebec. Annual Conference of the Canadian Society for Civil Engineering.

[35] Gupta, H.V., Sorooshian, S, and Yapo, P.O. (1999). Status of automatic calibration for hydrologic models: Comparison with multilevel calibration. J. hydrologic Eng. 4(2): 135-143.

[36] IN-NA, N. and Ngugen, V.-T.-V. (1989). An Unbiased Plotting Position Formula for the General Extreme Value Distribution. Journal of hydrology, 106(1989), pp.193 - 209.

[37] WMO168_Ed2009_Vol._II_Ch5_Up2008_en, Chapter 5: Extreme Value Analysis.

[38] Stedinger, J.R., Vogel, R.M. and Foufoula-Georgiou, E., 1993 Frequency analysis of extreme events. Handbook of Hydrology, New York, USA

[39] Naghavi, B. and Yu Xin, F. (1996). Selection of ParameterEstimation Method for LP3 Distribution. Journal of Irrigation and Drainage Engineering, Vol. 122, No. pp.24-30.

[40] [40] Kite, G. W. (1977). Frequency and risk analyses in hydrology. WaterResources Publications, https://books.google.se/books?id=WZt-AAAAIAAJ.

[41] Wilson, E.B. and Hilferty, M.M. (1931). "The distribution of Chisqure", Proceedings. National Academic of Science (New York), 17(12): 684- 688

[42] Abramowitz, M. and Stegun, I.A. (1965). Handbook of Mathematical Functions. Dover Publications, New York.

[43] ASCE. 1993. Criteria for evaluation of watershed models. J. Irrigation Drainage Eng.119(3): 429-442.

[44] Haktanir, T., (1992). Comparison of various flood frequency distributions using annual flood peaks data of rivers in Anatolia, Journal of Hydrology, 136(1992), 1-31.

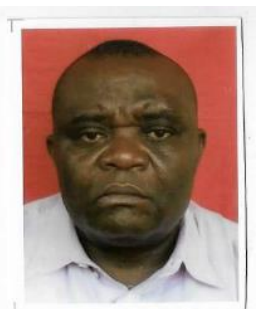

Dr. Ologhadien is an Associate Professor and formerly Acting Head, Department of Marine Engineering at the Rivers State University of Science and Technology, Port Harcourt. He graduated in 1988 with Bachelor of Technology (B. Tech) degree in Civil Engineering from the Rivers State University of Science and Technology, Port Harcourt, Nigeria. He received his M. Eng and PhD degrees in 2003 and 2012 respectively in Civil Engineering from University of Port Harcourt, Nigeria. He also received a PGD in Hydraulic Engineering from IHE, Delft, Netherlands in 1991. He has over 25 years of teaching, research and consultancy experience in Hydraulic engineering, Water resources Engineering, River and Coastal engineering. Dr Ologhadien has authored several publications in peer- review journals and over 100 technical reports to his credit.

Dr. Ologhadien is professional engineer registered with the Council for the Regulation of Engineering in Nigeria (COREN - R9516), a corporate member of the Nigerian Society of Engineers (R07389) and the International Association of Hydraulic Research (I - 7512). He is also recipient of two fellowships from the Netherlands Government in 1991 and 2003 respectively. 